\title{
Running From the Shadow: Psychological Distancing From Others to Deny Characteristics People Fear in Themselves
}

\author{
Jeff Schimel \\ University of Arizona \\ Jeff Greenberg \\ University of Arizona
}

\author{
Tom Pyszczynski \\ University of Colorado at Colorado Springs \\ Heather O'Mahen \\ University of Georgia
}

\author{
Jamie Arndt \\ University of Arizona
}

\begin{abstract}
Four experiments tested the hypothesis that people distance themselves from others who display characteristics they fear in themselves. In Study 1, participants were given false feedback that they were high or low in repressed anger and were given information about a person who became angry and responded in a violent or nonviolent manner. High anger feedback participants distanced themselves only from the violent person. In Study 2, high anger feedback led to distancing from a violent other but not a dishonest other, whereas dishonesty feedback led to distancing from a dishonest other but not a violent other. The results of Studies 3 and 4 replicated and extended the distancing effect with an anger induction: Participants who were insulted distanced themselves from an angry/violent person, and verbalizing their emotions about being insulted eliminated this effect. Implications for understanding defenses against undesirable self-attributions are discussed.
\end{abstract}

One of the core assumptions of social science is that people have a strong desire to feel connected to others (e.g., Aronson, 1972; Baumeister \& Leary, 1995; Bowlby, 1969; Brewer, 1979; Rank, 1931; Tajfel \& Turner, 1979). We are indeed social animals, and our relationships with other people are unquestionably important to us. However, despite our desire for connections with others, it seems clear that people often actively avoid closeness to others when such associations would have negative implications for the self. In the studies reported in this article we examined this tendency to defensively distance oneself from threatening others. Specifically, we tested the hypotheses that (a) people reduce their perception of similarity to others who have characteristics that they fear in themselves, (b) this defensive distancing is produced by fear of a specific negative characteristic rather than a more general concern with global self-evaluation, and (c) expressing emotions related to the feared characteristic reduces or eliminates this tendency to defensively distance from people who exhibit the feared characteristic.

Jeff Schimel, Jeff Greenberg, and Jamie Arndt, Department of Psychology, University of Arizona; Tom Pyszczynski, Department of Psychology, University of Colorado at Colorado Springs; Heather O'Mahen, Department of Psychology, University of Georgia.

This research was supported in part by National Science Foundation Grants SBR-9212798, SBR-9312546, SBR-9601474, SBR-9729946, and SBR-9731626. Special thanks go to Jessica Brown and Darren Abel for help with data collection for Study 2 and Study 4, respectively.

Correspondence concerning this article should be addressed to Jeff Schimel, Department of Psychology, University of Arizona, Tucson, Arizona 85721-0068. Electronic mail may be sent to jschimel@u.arizona.edu.

\section{Similarity and Connectedness}

One way we can feel connected to others is by perceiving ourselves to be similar to them, whether that similarity is based on traits, attitudes, ethnicity, nationality, or geography. Heider (1958) viewed perceptions of similarity as creating a unit relationship between individuals and posited that such relationships have important implications for how people react to their own and others' characteristics. From the perspective of Tesser's (1988) selfevaluation maintenance model, the perception of similarity to another person is a crucial determinant of closeness and one of three variables that dynamically interact to determine the effect of social relationships on self-evaluations. A variety of theories and research findings suggest that judgments and inferences about a person are strongly influenced by perceptions of that person's similarity to others, even when the similarity is on a dimension unrelated to the judgment in question (e.g., Festinger, 1954; Gilovich, 1981; Kahneman \& Tversky, 1972; Kelley, 1967; Wood, 1989). Perceiving ourselves to be similar to a person who has positive attributes or who engages in laudable behavior implies that we may have similar attributes or be capable of similar feats. Thus, by perceiving ourselves to be similar to attractive, successful, or otherwise valuable people we can identify with them and "bask in their reflected glory" (Cialdini et al., 1976).

Consistent with this reasoning, research has shown that most people perceive themselves to be especially similar to others who have positive attributes, such as physical attractiveness and intelligence (Byrne \& Blaylock, 1963; Granberg \& King, 1980; Marks \& Miller, 1982; Marks, Miller, \& Maruyama, 1981). Similarly, Cialdini et al. (1976) showed that when a local sports team is 
successful, people try to enhance their association with the team. In a related vein, Tesser and his colleagues (e.g., Tesser, 1988) have shown that people are motivated to perceive high similarity between themselves and successful others, unless doing so engenders a threatening social comparison on an ego-relevant dimension. These findings are, of course, generally consistent with social identity theory, which posits that our social identifications are an important source of self-worth (e.g., Crocker \& Luhtanen, 1990; Tajfel, 1982).

Although there are many benefits to perceiving similarity and connection to laudable others, there may be costs to perceiving similarity to less distinguished exemplars of humanity. Whereas our connections to some people provide comfort and make us feel good about ourselves, our connections to other people engender anxiety and negative feelings about ourselves. Thus, we may want to perceive ourselves to be dissimilar to others who have qualities we perceive as negative. In support of this idea, research has shown that people try to minimize links to unsuccessful sports teams (Cialdini et al., 1976) and perceive dissimilarity to people who have negative personal attributes (e.g., Byrne \& Blaylock, 1963; Marks \& Miller, 1982; Marks et al., 1981). Research has also shown that people trying to quit smoking decrease their perceived similarity to the "typical smoker" (Gibbons, Gerard, Lando, \& McGovern, 1991).

Recently, Pyszczynski and colleagues (Pyszczynski, Greenberg, Solomon, Sideris, \& Stubing, 1993; Pyszczynski et al., 1995) have shown that people also distance themselves from individuals who are suffering from a life-threatening disease. Specifically, in two studies in which student participants first saw the alleged personality trait ratings of another student, participants distorted their own trait ratings to be more dissimilar to the other student if that student reported having cancer than if the student reported having a sprained ankle. Presumably, perceiving oneself to be similar to someone who has suffered a dreadful disease makes one feel more vulnerable to a similar fate, and people consequently adjust their self-perceptions to reduce this similarity and thus reduce their subjective sense of vulnerability.

\section{Distancing and Self-Esteem}

The research of Pyszczynski and colleagues (Pyszczynski et al., 1993, 1995) suggests that people will distance themselves from others to deny vulnerability to a feared fate. The work of Cialdini et al. (1976) and Snyder, Lassegard, and Ford (1986) suggests that distancing from others can also serve to protect self-esteem. Specifically, Cialdini et al. showed that students increased their school identity (i.e., by wearing school colors and sports paraphernalia) when their football team was successful relative to when the team was unsuccessful. In a conceptual replication of Cialdini et al.'s research, Snyder et al. (1986) found that people both cut themselves off from unsuccessful groups and increase their connection to successful groups. Together, these studies demonstrate distancing from groups when groups display undesirable attributes that could reflect negatively on the individual's self-esteem. Similarly, in the interpersonal realm, people may want to distance themselves from others with undesirable attributes, particularly when they have reason to fear that they may possess those attributes themselves. Presumably, such a strategy would protect self-esteem from the threat of believing that one has such undesirable attributes.
Consistent with this reasoning, theory and research suggest that homophobia may be highest among men who fear latent homosexual tendencies in themselves (Adams, Wright, \& Lohr, 1996; Gilgun \& Reiser, 1990). Another interesting observation is that parents and offspring who share similar personality characteristics often have trouble getting along. This may occur because parents and children see what they suspect are their own undesirable traits in each other.

The notion that people psychologically distance themselves from those who have characteristics they fear in themselves is related to Carl Jung's (1951/1959) proposition that we all carry with us a "shadow," a negative side of ourselves about which we have doubts and fears, and that we spend a great deal of energy working to deny and control this shadow. Markus and Nurius (1986) proposed a similar notion in their conceptualization of undesired possible selves. These and other authors have applied such notions primarily to understanding individual motivation, affect, and the role of undesired possible selves in self-regulatory behavior (e.g., Higgins, 1996; Markus \& Nurius, 1987; Ogilvie, 1987). However, Jung devoted a great deal of attention to the role the shadow plays in relationships with others, and he proposed that one way we try to deny our shadow is by seeing it in others-that is, by projecting our negative qualities onto others. Jung used this analysis to help explain aspects of both individual neurosis and larger social evils, such as the persecution of Jews by the Nazis (e.g., Jung, 1959/1970).

We, too, are interested in the role of individuals' fears about themselves in their orientation toward others. However, we propose a different form of defense against one's feared shadow; specifically, that when people see qualities in others that remind them of possible negative aspects of themselves, they respond to this threat by perceiving themselves to be different from such persons. The primary purpose of the present research was to investigate the role of fear of undesirable self-characteristics in distancing from people who possess these characteristics and to begin examining the processes that underlie this defense.

\section{Distancing From Violent Others to Deny One's Own Potential for Violence}

One domain in which this defensive distancing phenomenon may be particularly evident is in the very common experience and expression of unpleasant emotions such as guilt, jealousy, and anger. Indeed, Jung (1951/1959) proposed that much of what we fear about ourselves stems from our emotions:

Closer examination... of the inferiorities constituting the shadow ... reveals that they have an emotional nature.... Affects occur usually where adaptation is weakest, and at the same time they reveal the reason for its weakness, namely a certain degree of inferiority and the existence of a lower level of personality. (pp. 8-9)

In the studies reported in this article we focused primarily on defensive distancing from violent others to deny the potential for destructive expression of one's own anger. We deemed angerrelated experience as ideal for studying defensive distancing, because although anger is a common emotion that all people experience, the inappropriate expression of anger often results in negative personal consequences and social disapproval that might lead people to fear or deny the potential consequences of their' 
anger. For example, people may worry about the direct social consequences of telling off their boss or getting into counterproductive arguments with a lover or friend. In addition to social costs, people may also wish to deny their potential for acting out of anger to avoid the social stigma associated with being a "hothead" or a "rage-oholic," which would reflect negatively on their sense of self. One particularly important way in which anger could leave one feeling stigmatized is through its association with violence and aggression. Violent aggression is widely considered the most evil and socially deplorable of all forms of human behavior. Given the strong link between violence and anger, the often horrendous consequences of violence, and the strong social sanctions against such behavior, it is no wonder many people would rather deny than acknowledge their anger. We suggest, then, that one reason why people may wish to deny their anger is because of their fear that their anger has the potential to lead to inappropriate violent action. If this is the case, then reminding people of their potential for anger should lead them to strategically distance themselves from others who respond to anger with destructive violence but should not lead to distancing from those who respond to anger in a constructive or socially appropriate manner.

\section{Study 1}

If people defend against the fear that their anger may lead to harmful violence by distancing themselves from people who engage in angry aggression, then leading people to believe that they harbor a great deal of anger beneath the surface should increase their tendency to distance themselves from violent others. Furthermore, if it is the potential for violence that underlies the threatening nature of anger, leading people to believe that they are high in repressed anger should not lead to distancing from people who respond to their anger in appropriate, socially sanctioned ways. In Study 1 we tested this hypothesis by providing participants with feedback that they had either a large or small amount of repressed anger and then using a methodology developed by Pyszczynski et al. $(1993,1995)$ we assessed their tendency to view themselves as different from another angry person who expresses his or her anger in either a socially unacceptable violent or socially acceptable nonviolent way. We predicted that participants who were led to believe that they had a latent tendency for anger would psychologically distance themselves from a person whose anger led to violence by perceiving their own personality traits to be very different from those of the violent person.

\section{Method}

Participants. The participants were 42 introductory psychology students (19 men and 24 women) at the University of Colorado at Colorado Springs who had taken part in a prescreening session in the beginning of the semester. During this prescreening session, potential participants filled out a packet of questionnaires, which included the Multi-Dimensional Anger Inventory (MAI; Siegel, 1986). The purpose of this questionnaire was to set up the high versus low repressed-anger feedback manipulation that was administered in the later experimental sessions. Participants were randomly assigned to conditions in a 2 (feedback: high vs. low) $\times 2$ (target: violent vs. nonviolent) factorial design and then were tested individually or in groups ranging in size from 2 to 6 . Participants received course credit for completing the prescreening packet and for taking part in the study itself.

Procedure. On participants' arrival at the experimental session, it was explained to them that the purpose of the experiment was to learn more about how people use information to make judgments about others and that in order to examine this process participants would be asked to look over some personality information about another student (the target person) and then make some judgments about that person. The experimenter further explained that a second purpose of the study was to obtain participants' opinions and attitudes about a scale measuring people's tendencies toward anger and hostility. The experimenter reminded participants of the prescreening questionnaires and the MAI they had completed earlier in the semester. The experimenter then explained that the MAI measured a person's repressed feelings of anger and hostility. Participants were told that because the MAI was a newly developed questionnaire the experimenter was interested in getting their opinions about it. To this end, each participant was given a sealed envelope containing his or her MAI score and told to open the envelope and look at the score.

Each envelope contained a computer printout titled "Multi-Dimensional Anger Inventory (MAI) Percentile Ranking Scores," with the participant's name, gender, and date of testing at the top. Below the title was a simple line graph with a score emphasized directly on the graph in boldface type. This score was also printed in boldface type and underlined directly below the graph. Participants in the high anger feedback condition received a percentile ranking score of 94 , and participants in the low anger feedback condition received a percentile ranking score of 42 . At the bottom of the printout was an interpretation of the score. For participants in the high anger feedback condition the interpretation read, "This person scores above the normal range of hostility expression. This score is an indication of repressed anger or higher than normal feelings of anger or hostility." For participants in the low anger feedback condition the interpretation read, "This person falls within the normal range of hostility expression. This score is an indication of moderately low to average feelings of anger or hostility." After looking at this printout, participants were told to put the printout back into the envelope and that they would have a chance to discuss their thoughts about the MAI at the conclusion of the experiment.

Participants then received a packet of information about the target person. This packet contained some demographic information, a description of an emotional situation, and a personality inventory of the target person. The purpose of including the demographic information was to set up an illusion of basic similarity to the target person. The demographic page presented the target person as a student at the participants' university who was 1 year older than the participant, of the same gender, of the same political orientation (i.e., liberal or conservative), and a college sophomore.

The next piece of information in this packet was a handwritten description of an emotional situation in which the target person had been involved. This description introduced the violent-nonviolent manipulation. In the violent condition, the target person wrote:

The other day 1 got home from school and found out that my little nephew was staying with us for the week. He is usually a pretty well behaved kid, but when I got home I went into my room to get something and noticed that he had gotten some markers from my desk and was drawing animals on the walls in my room. I got angry and grabbed the markers from his hands and took hold of his arm. I shook him by the arm until he started crying, and then slapped him. I must have been pretty pissed off because the next day I noticed a bruise under his eye where I had hit him.

In the nonviolent condition the beginning two sentences were the same, but the remainder of the description was as follows:

I got angry and grabbed the markers from his hands and told him to stop. After dinner, when I was calmed down, I explained to him that markers are not for writing on walls. Later, I made him help me clean the walls.

The last piece of information that participants inspected was a bogus personality inventory of the target person, as was used in Pyszczynski et al 
(1993, 1995). On this form, the target person was rated on 20 different personality traits chosen from Alicke's (1985) list of 362 trait adjectives that had previously been rated for desirability. The target received a score on a scale that ranged from 0 to 100 for each separate trait. This score was indicated by a vertical line printed along the scale in boldface type. Printed below each line was the numerical score for that trait. The personality inventory consisted of 10 moderately desirable traits and 10 moderately undesirable traits. ${ }^{1}$ To make it easier for participants to distance themselves in either direction, the target person was always portrayed as falling between the 75 th and 50 th percentiles on positive traits and between the 50 th and 25 th percentiles on negative traits. The same arbitrarily constructed personality inventory (within the above guidelines) was used for all participants. This procedure was similar to that used by Pyszczynski et al. $(1993,1995)$.

All participants were given as much time as they needed to read through the packet of information on the target person. When they finished, the experimenter began frantically shuffling through some papers. After about a minute, the experimenter turned to the participants and explained that the next part of the experiment involved filling out a short personality form but that the form appeared to be missing. The experimenter asked the participants to wait there while he left to find some extra forms in his office. After about $3 \mathrm{~min}$, the experimenter returned and said that he was unable to find the appropriate form. The experimenter then informed the participants that the personality form they were supposed to fill out simply asked them to rate themselves on the same 20 traits on which the target person had been rated. Thus, as a solution to the dilemma, the experimenter instructed the participants to use the target person's personality inventory as their own form. The participants were instructed to simply circle a point on the scale beside each trait indicating how much each trait was descriptive of themselves. This ploy enabled us to keep the target person's ratings on the various traits salient while participants made their self-ratings. We used participants' self-ratings on these traits to construct a composite measure of distancing from the target person.

In the final part of the study, participants were asked to fill out a form containing questions about the target person and the anger feedback (on 9-point scales) that served as manipulation checks. Higher ratings reflected affirmative responses to the particular items. To check the effectiveness of the violent-nonviolent manipulation, participants were first asked "How violent was the person you read about?" As a direct measure of similarity, participants were asked "How similar do you see yourself to this person?" The last question in this series served as a check on participants' overall liking for the target person and asked "How likable is this person?" As a second measure of the overall favorability of participants' impressions, participants were asked to rate the target person on 20 trait adjectives (10 positive and 10 negative) on a scale ranging from 1 (not very characteristic) to 9 (very characteristic). The traits used were clearly positive (e.g., caring, friendly, honest) and clearly negative (e.g., self-centered, dishonest, controlling). The addition of this measure was partly intended to offer additional credence to our cover story that the participants would be asked to read about another student and then make some judgments about that student. One final question on this form pertained to the false feedback participants received on the MAI. This question asked participants to indicate on a scale ranging from 0 to 100 where they thought the average college student would score on the MAI. The purpose of this question was to make sure participants perceived a score of 94 as high and a score of 42 as low or average compared to most other college students. When all the participants had completed this last series of questions they were thoroughly debriefed, given credit, and dismissed.

\section{Results and Discussion}

Manipulation checks. We performed separate 2 (feedback: high vs. low) $\times 2$ (target: violent vs. nonviolent) analyses of variance (ANOVAs) on participants' ratings of how violent the target was, how similar the target was to themselves, and how likable the target was. There was a main effect of target on violence ratings, $F(1,39)=221.63, p<.001$, indicating that participants viewed the violent target as more violent than the nonviolent target ( $M \mathrm{~s}=7.2$ and 2.7, respectively). Main effects of violence on similarity, $F(1,39)=12.19, p<.001$, and likability ratings, $F(1,38)=19.46, p<.001$, also were found, showing that participants saw themselves as more similar to the nonviolent target than to the violent target ( $M \mathrm{~s}=6.1$ and 3.8, respectively) and liked the nonviolent target more than the violent target ( $M \mathrm{~s}=6.9$ and 4.9 , respectively). Thus, the violence manipulation was clearly effective. Individual cell means and standard deviations are presented in Table 1.

Participants' ratings of the target's personality were in line with the results outlined above. We constructed two separate composite measures by summing participants' ratings of the target on the 10 positive traits and the 10 negative traits. Separate $2 \times 2$ ANOVAs revealed a main effect of violence on ratings of both positive and negative traits, $F(1,38)=44.24, p<.001$, and $F(1,38)=68.33$, $p<.001$, respectively. Participants rated the nonviolent target higher on positive traits and lower on negative traits $(M \mathrm{~s}=68.4$ and 33.1, respectively) than the violent target ( $M s=44.7$ and 59.9, respectively).

A $2 \times 2$ ANOVA on participants' estimates of how other college students would score on the MAI revealed a main effect of feedback, $F(1,39)=4.31, p<.05$, showing that participants in the high anger feedback condition viewed other college students as having more repressed anger than participants in the low anger feedback condition ( $M \mathrm{~s}=60.9$ and 51.4, respectively). Despite this main effect, participants' mean estimates of how other college students would score on the MAI revealed average estimates that were well below a score of 94 and slightly above a score of 42 . Participants in the high anger feedback condition gave mean estimates of 64.20 (violent condition) and 57.63 (nonviolent condition), and those in the low anger feedback condition gave mean estimates of 53.22 (violent condition) and 49.76 (nonviolent condition). Given that high anger feedback participants were given scores of 94 and low anger feedback participants were given scores of 42 , it seems that our anger feedback manipulation was successful in making participants in the high anger feedback conditions believe their score was very high compared to the average college student and in making participants in the low anger feedback conditions believe their that their score was low compared to other college students.

Distancing measure. We constructed a composite measure of distancing from the target by summing the absolute value of the difference between the target's score and the participant's

\footnotetext{
${ }^{1}$ The 10 moderately desirable traits that were used on the distancing measure were witty, bold, neat, self-satisfied, philosophical, meticulous, prudent, obedient, reserved, and progressive. The 10 moderately undesirable traits were clumsy, restless, tiresome, extravagant, overcautious, unpoised, boastful, strict, conforming, and forgetful. We intentionally chose traits that were somewhat vague, unrevealing, and not related to anger (Studies 1, 3, and 4) or dishonesty (Study 2), because we wanted to reduce the possibility that defensive distancing could be attributed to real differences perceived between participants and the target along particular personality dimensions.
} 
Table 1

Manipulation Checks and Primary Dependent Measures: Study 1

\begin{tabular}{|c|c|c|c|c|c|c|c|c|}
\hline \multirow[b]{4}{*}{ Measure } & \multicolumn{8}{|c|}{ Feedback } \\
\hline & \multicolumn{4}{|c|}{ High } & \multicolumn{4}{|c|}{ Low } \\
\hline & \multicolumn{2}{|c|}{$\begin{array}{l}\text { Violent target } \\
\text { person }^{\mathrm{a}}\end{array}$} & \multicolumn{2}{|c|}{$\begin{array}{c}\text { Nonviolent target } \\
\text { person }^{b}\end{array}$} & \multicolumn{2}{|c|}{$\begin{array}{l}\text { Violent target } \\
\text { person }^{c}\end{array}$} & \multicolumn{2}{|c|}{$\begin{array}{l}\text { Nonviolent target } \\
\text { person }^{\mathrm{d}}\end{array}$} \\
\hline & $M$ & $S D$ & $M$ & $S D$ & $M$ & $S D$ & $M$ & $S D$ \\
\hline Violent & 7.40 & 1.1 & 2.36 & 0.8 & 7.00 & 1.0 & 3.15 & 1.0 \\
\hline Similar & 3.50 & 1.9 & 5.90 & 2.4 & 4.11 & 2.3 & 6.30 & 2.0 \\
\hline Likable & 5.55 & 1.1 & 6.90 & 1.3 & 4.33 & 2.1 & 7.07 & 1.3 \\
\hline Positive traits & 47.30 & 7.6 & 68.81 & 6.9 & 42.12 & 14.8 & 68.07 & 14.2 \\
\hline Negative traits & 56.00 & 10.9 & 31.27 & 9.1 & 63.87 & 8.8 & 35.07 & 11.6 \\
\hline Distancing & 352.50 & 82.6 & 265.45 & 81.0 & 265.88 & 61.5 & 275.53 & 71.4 \\
\hline
\end{tabular}

Note. For all measures, high values reflect high levels of the variable in question. The $n s$ listed apply only to the distancing measure, because some of the manipulation check measures were not completed by 2 participants in Study 1.

${ }^{\mathrm{a}} n=10 .{ }^{\mathrm{b}} n=11 . \mathrm{c}_{n}=9 . \mathrm{d}_{n}=13$.

score for each of the 20 traits. ${ }^{2}$ A 2 (feedback: high vs. low) $\times 2$ (target: violent vs. nonviolent) ANOVA revealed only the predicted interaction, $F(1,39)=4.40, p<.05$. The means for this interaction are displayed in Table 1. Pairwise comparisons showed that participants in the high anger feedback-violent condition distanced themselves significantly more from the target than did participants in the high anger feedbacknonviolent, low anger feedback-violent, and low anger feedbacknonviolent conditions, $t(39)=2.43, p<.05 ; t(39)=2.61, p<.05$; and $t(39)=2.34, p<.05$, respectively. No other pairwise comparisons approached significance.

Supplemental analysis. An alternative explanation for why participants distanced themselves from the target person is that they were simply rating themselves higher on the positive traits and lower on the negative traits than the target. Thus, distancing from the target in the anger feedback-violent-target condition may reflect a general tendency for participants to inflate their selfesteem in response to negative feedback by rating themselves positively relative to the target. To test this alternative explanation, we reverse coded participants' ratings on the 10 negative traits and summed them with the 10 positive traits to form a composite favorability score. An ANOVA performed on this favorability score yielded no main effects or interactions, indicating that participants' tendency to distance themselves from the target person was not due to more favorable self-ratings on the 20 personality traits (all $p s>.45$ ). This analysis supports our prediction that participants' tendency to psychologically distance themselves is due to fear of undesirable characteristics (i.e., their own potential for inappropriate violence) and not to a general tendency to inflate their self-esteem.

The findings from Study 1 demonstrate that participants distanced themselves from a person who expressed anger in a violent manner after being reminded of their own potential for anger. The pairwise comparisons revealed that only participants who received high anger feedback distanced themselves from the violent person. This supports our contention that one's fear of having an undesirable attribute lies at the root of defensive distancing from others who have this attribute. ${ }^{3}$ The fact that high anger feedback participants did not distance themselves from a nonviolent angry person suggests that simply thinking of oneself as an angry person is not enough to produce distancing from another angry person. Similarity to an angry person is threatening only if that other person is driven to violence by anger. Similarly, when not thinking of themselves as particularly angry people, participants were apparently not threatened by rating their personalities as similar to that of the violent person. The present findings suggest that simply feeling angry, or viewing oneself as angry, is not threatening unless being angry implies that one has the potential to commit acts of violence. This overall pattern of results suggests that people distance themselves from others who remind them of a negative potential they fear in themselves-in Jungian terms, their shadow.

It is interesting that the single-item similarity measure did not yield the interaction that was found for the trait-rating composite, although the least similarity was in fact perceived in the high anger-violent-target condition. Instead, there was just a main effect such that less similarity to the violent person was perceived.

\footnotetext{
${ }^{2}$ We also conducted a post hoc analysis of gender in the four studies. We conducted ANOVAs using gender as an added moderating variable on distancing. There were no effects of gender in the first three studies; however, there was a significant main effect of gender in Study 4, indicating that men generally distanced themselves more than women, $F(1$, $35)=4.56, p<.04$. In all the studies, gender did not interact with the other conditions, and the numbers of men and women were distributed roughly equally across the conditions.

${ }^{3}$ Of course, a capacity for angry violence may not always be viewed as an undesirable attribute. This may depend on the culture, the individual's role within the culture, and the nature of the violence. For example, in American culture a boxer or a middle linebacker may pride himself on his capacity for using anger to generate effective violence. However, this research is predicated on the general assumption that a capacity for inappropriate angry aggression is undesirable and the specific assumption that our participants would not want to believe they were capable of unwarranted violence against a child when angry.
} 
Pyszczynski et al. (1995) also found a direct single-item measure to be less sensitive than a composite measure of distancing on specific traits, yielding a similar pattern of means but not significant effects. As Pyszczynski et al. suggested, the direct similarity measure may simply be less reliable because it is only a single item, or it may show weaker results because, as an obvious measure of similarity, it may be influenced by self-presentational concerns such as a desire to not appear biased.

\section{Study 2}

Although Study 1 demonstrated that people who fear anger in themselves defensively distance themselves from violent others, it is unclear from these findings whether this distancing is driven by their fear of this specific negative characteristic or by the more general threat to self-esteem posed by the feedback that they were high in repressed anger. Although our hypothesis is that people defensively distance themselves from others to deny their own potential for a feared behavior or characteristic, an alternative explanation for the findings of Study 1 is that participants may have been responding to a more general threat to their self-esteem by perceiving themselves as different from another person with any undesirable characteristics. Although the results of our supplementary analysis suggest that distancing was not the result of a general self-esteem threat, we decided to test this alternative hypothesis experimentally. If it were the case that participants psychologically distance themselves by perceiving themselves as different from people with undesirable traits, then we would expect participants to distance themselves from a broad range of other people with virtually any characteristic they perceive as undesirable. However, if people defensively distance themselves to deny their own potential for a particular negative characteristic or behavior, this distancing should occur only in response to other people with that particular feared characteristic. We designed Study 2 to test these alternative explanations by using a second characteristic, dishonesty, that is unrelated to anger. Along with distancing themselves to deny a potential for violence, people who are reminded of their potential for dishonesty should distance themselves from a dishonest other.

To this end, participants were given false feedback on a personality test indicating that they were high in either anger or dishonesty and then were exposed to a personality profile of another person who acted in either a violent or dishonest way. If the effects of Study 1 reflect a general distancing from people with negative characteristics, then defensive distancing from both target persons should be found. However, if the findings of Study 1 reflect a maneuver to specifically deny one's own potential for a feared behavior or characteristic, then anger feedback participants should distance themselves only from the violent person and, to the extent that the dishonesty feedback is also threatening, dishonesty feedback participants should distance themselves only from the dishonest person.

\section{Method}

Participants. The participants were 47 introductory psychology students ( 22 men and 25 women) at the University of Arizona. As in Study 1, all participants had previously taken part in a mass testing session in the beginning of the semester in their introductory psychology class. Participation in the mass testing session served to set up the high repressed anger versus high repressed dishonesty feedback manipulation that was administered later in the experiment. Participants were randomly assigned to conditions in a 2 (feedback: anger vs. dishonesty) $\times 2$ (target: angry vs. dishonest) factorial design and then tested in groups ranging in size from 2 to 4. All participants received course credit for completing the experiment.

Procedure. As in Study 1, participants were told that the purpose of the experiment was to learn more about how people use information to evaluate others. It was further explained that, to examine this judgment process, participants would be asked to look through some personality information about another student (the target person) and then make some judgments about this person. The experimenter went on to explain that a second purpose of the experiment was to obtain participants' attitudes and opinions about a couple of different personality questionnaires that participants had previously filled out in a mass testing session in their introductory psychology class. The first questionnaire was described as a measure of repressed anger and hostility, and the second questionnaire was described as a measure of repressed dishonesty or tendencies to lie, cheat, or steal. It was further explained that these questionnaires are used by large corporations to assess employees' job satisfaction and to see what kinds of employees are more likely to steal from the company. Participants were then told that because the experimenter would be conducting some research on these personality questionnaires later in the semester, it would be helpful if she could get information about their attitudes and opinions about these questionnaires. To this end, participants were instructed to enter a private cubicle and were given a sealed envelope containing either their anger score or their dishonesty score.

Each envelope contained a computer printout entitled "Johnson's Anger and Hostility Scale" or "Johnson's Dishonesty Scale." The layout and appearance of the printouts were the same as in Study 1. Participants in both the anger feedback condition and the dishonesty feedback condition received a percentile score of 92 on the respective test. There was also an interpretation on the bottom of each printout. For participants in the anger feedback condition this interpretation read:

NOTE: This test measures repressed tendencies for anger or hostility. A high score on this test may indicate that the person has tendencies toward hostility and repressed anger but is usually unaware of these tendencies.

SUMMARY: This person scores above the normal range of anger or repressed hostility, indicating that this person may have a tendency for hostile or aggressive behavior, especially when frustrated or in response to threat.

For participants in the dishonesty feedback condition, the interpretation read:

NOTE: This test measures a tendency toward repressed dishonesty. A high score on this test may indicate that the person has repressed guilt or feelings of injustice that may lead to dishonest behavior but is usually unaware of these tendencies.

SUMMARY: This person scores above the normal range of dishonesty or repressed guilt, indicating that this person may be a risk for dishonest behavior, especially when working under conditions that lack structure or supervision.

After inspecting the printout, participants were instructed to put it back into the envelope and told that they would have a chance to discuss their thoughts about their score and the questionnaire at the end of the experiment.

Participants then received a packet of information about the target person. As in Study 1, this packet contained three pieces of information about the target person: demographic information, a self-written descrip- 
tion of an emotional situation, and a personality form. ${ }^{4}$ For participants in the violent-target condition, the self-written description of an emotional situation was the same violent description (child abuser) used in Study 1. For participants in the dishonest-target condition, the description read:

The other day I was working out in the student rec center and I was snooping around opening some of the lockers in the locker room. I opened one of the lockers and found someone's backpack. I guess they didn't have a lock so they took a gamble and left it in one of the lockers. Just out of curiosity I looked in the backpack and found some money. There was about $\$ 90.00$ in there and something came over me and I took the money. I guess I knew I could get away with it because there was nobody there. I was a little nervous at first, but I got away with it so everything turned out okay.

After looking through this information, participants were asked to fill out a short personality questionnaire. Using the same procedure used in Study 1, the experimenter pretended to be missing this personality form and left for about $3 \mathrm{~min}$ to find it. After returning without the appropriate form, the experimenter resolved the dilemma by having participants make their self-ratings on the target's personality form.

In the final portion of the experiment, participants completed a form containing questions about the target person and the feedback they received that served as manipulation checks. The first three questions asked participants to rate how appropriate the target person's behavior was, how similar to the target person they considered themselves to be, and how likable they thought this person was. Two additional questions asked participants how accurate they thought their score was and the extent to which they thought the questionnaire was a good measure of anger or dishonesty (depending on which questionnaire they received). Ratings on each question were made on 9-point scales, with higher numbers indicating positive responses. After completing this last form, participants were fully debriefed, given credit, and dismissed.

\section{Results and Discussion}

Manipulation checks. We performed separate 2 (feedback: anger vs. dishonesty) $\times 2$ (target: violent vs. dishonest) ANOVAs on participants' ratings of how appropriate the target's behavior was, how similar to the target person they considered themselves to be, and how likable they thought the target was. There was a main effect of target person on participants' ratings of appropriateness, $F(1,43)=8.94, p<.005$, indicating that participants viewed the dishonest target's behavior as less appropriate than the angry target's behavior $(M \mathrm{~s}=2.7$ and 1.5 , respectively). There was also a main effect of target on ratings of similarity, $F(1$, $43)=5.23, p<.05$, showing that participants rated themselves as less similar to the dishonest person than to the angry person $(M \mathrm{~s}=4.0$ and 2.8, respectively). There were no main effects or interactions for participants' ratings of target likability ( $p$ s $>.10$ ).

We also performed ANOVAs on participants' ratings of how accurate they thought their feedback was and how much they thought the mass testing questionnaire was a good measure of anger or dishonesty. There was a main effect of target description for accuracy ratings, $F(1,43)=4.23, p<.05$, indicating that participants who read about the dishonest target thought their feedback was less accurate than participants who read about the angry target ( $M \mathrm{~s}=4.0$ and 5.4 , respectively). Perhaps this reflects a contrast effect whereby participants who read about the dishonest other, who was rated especially negatively on the appropriateness and similarity items, saw their negative feedback as relatively less deserved. A main effect of the extent to which participants thought the questionnaire was a good measure only approached significance, $F(1,43)=3.78, p<.06$. The pattern of means showed that participants who read about the dishonest target thought the mass testing questionnaire was a poorer quality measure than participants who read about the angry target $(M \mathrm{~s}=3.9$ and 5.3 , respectively). These results seem to indicate that participants were generally more negative toward the dishonest target than the violent target.

Distancing measure. As in Study 1, we constructed a composite measure of distancing from the target person by summing the absolute value of the difference between participants' and the target person's ratings on the 20 personality traits. An ANOVA performed on this distancing score revealed only the predicted 2 (feedback: anger vs. dishonesty) $\times 2$ (target: angry vs. dishonest) interaction, $F(1,43)=17.81, p<.001$. The means for this interaction are displayed in Table 2. Pairwise comparisons showed that participants who received anger feedback distanced themselves more from the angry target than from the dishonest target, $t(43)=2.77, p<.01$, and participants who received dishonest feedback distanced themselves more from the dishonest target than from the angry target, $t(43)=3.19, p<.01$. Pairwise comparisons also showed that participants distanced themselves more from the angry target when they received anger feedback than when they received dishonesty feedback, $t(43)=2.14, p<.05$, and that participants distanced themselves more from the dishonest person when they received dishonesty feedback than when they received anger feedback, $t(43)=3.84, p<.001$.

Supplemental analyses. As in Study 1, we tested the alternative explanation that distancing from the target person may have occurred because participants rated themselves higher on the positive traits and lower on the negative traits than the target person. To test this alternative explanation, we reverse coded participants' ratings on the 10 negative traits and summed them with the 10 positive traits to form a composite favorability score. An ANOVA performed on this favorability score yielded no main effects or interactions, indicating that participants' tendency to distance themselves from the target person was not due to more favorable self-ratings on the 20 personality traits (all $p s>.13$ ).

The findings from Study 2 replicated those of Study 1 and demonstrated that the defensive distancing observed in this research occurs to deny one's potential for a specific feared characteristic or behavior rather than to more generally deny one's possession of negative characteristics. Whereas participants who were led to believe that they possessed a high level of repressed anger distanced themselves from a violent other but not from a dishonest other, participants who were led to believe that they possessed a high level of repressed dishonesty distanced them-

\footnotetext{
${ }^{4}$ The target's personality form used in Study 2 and Study 4 was different from the personality profile used in Study 1 and Study 3. We had reason to believe that participants had some suspicions about the personality profile used in Study 1, so we made some minor changes to this form. Thus, the personality form in Study 2 was depicted as having been filled out by the target person him-/herself. The revised form contained the target's name (crossed out), gender, and age at the top of the page and the target's own markings on the scale for each trait. The purpose of these changes was to increase participants' perception that the target's personality scores were self-generated and therefore more likely to reflect the "true" personality of the target person.
} 
Table 2

Manipulation Checks and Primary Dependent Measures: Study 2

\begin{tabular}{|c|c|c|c|c|c|c|c|c|}
\hline \multirow[b]{4}{*}{ Measure } & \multicolumn{8}{|c|}{ Feedback } \\
\hline & \multicolumn{4}{|c|}{ Anger } & \multicolumn{4}{|c|}{ Dishonesty } \\
\hline & \multicolumn{2}{|c|}{$\begin{array}{c}\text { Angry target } \\
\text { person }^{\mathrm{a}}\end{array}$} & \multicolumn{2}{|c|}{$\begin{array}{l}\text { Dishonest target } \\
\text { person }^{\mathrm{b}}\end{array}$} & \multicolumn{2}{|c|}{$\begin{array}{c}\text { Angry target } \\
\text { person }^{\mathrm{c}}\end{array}$} & \multicolumn{2}{|c|}{$\begin{array}{c}\begin{array}{c}\text { Dishonest target } \\
\text { person }^{\mathrm{d}}\end{array} \\
\end{array}$} \\
\hline & $M$ & $S D$ & $M$ & $S D$ & $M$ & $S D$ & $M$ & $S D$ \\
\hline Appropriate & 2.33 & 1.7 & 1.38 & 0.7 & 3.09 & 1.5 & 1.63 & 1.5 \\
\hline Similar & 3.83 & 1.6 & 2.84 & 1.5 & 4.27 & 2.0 & 2.81 & 2.2 \\
\hline Likable & 3.75 & 1.6 & 3.31 & 1.4 & 4.45 & 1.6 & 3.45 & 1.7 \\
\hline Accurate & 6.25 & 2.2 & 3.92 & 2.2 & 4.45 & 2.3 & 4.00 & 2.5 \\
\hline Good measure & 6.25 & 2.2 & 3.92 & 1.6 & 4.20 & 2.2 & 3.90 & 3.0 \\
\hline Distancing & 343.67 & 63.7 & 259.08 & 67.3 & 275.45 & 70.3 & 379.27 & 101.1 \\
\hline
\end{tabular}

Note. For all measures, high values reflect high levels of the variable in question.

${ }^{\mathrm{a}} n=12 . \quad{ }^{\mathrm{b}}{ }_{n}=13 .{ }^{\mathrm{c}}{ }_{n}=11 . \quad \mathrm{d}_{n}=11$.

selves from a dishonest other but not from a violent other. Supplemental analyses further revealed that the effects observed in this research reflect a tendency to psychologically distance oneself from people with negative characteristics one fears in oneself rather than a general tendency to inflate one's self-esteem by endorsing high levels of positive characteristics and low levels of negative characteristics. Thus, the findings of Study 2 support our hypothesis that people respond to the fear of negative aspects of themselves (in Jungian terms, their shadow) by perceiving themselves as different from others who clearly possess these characteristics.

By demonstrating psychological distancing specific to the threat of a feared characteristic in the self, the present work contrasts with approaches that emphasize the substitutability of self-esteem defenses (e.g., Steele, 1988; Tesser \& Cornell, 1991). For example, Steele (1988), in his self-affirmation theory, argued that a specific threat to one's self concept can be addressed by a variety of defenses that restore global "self-integrity." However, Stone, Wiegand, Andrew, Cooper, and Aronson (1997) recently demonstrated that directly addressing the threat to self is preferred over an indirect compensatory action. Similarly, the results of Study 2 show that the current type of defense appears to be specific to the type of threat aroused. People who were told they had a potential for dishonesty did not distance themselves from a violent other, and those who were told they had latent hostility did not distance themselves from a dishonest other. Clearly, then, whereas indirect compensatory defenses on other dimensions can serve global selfesteem (Baumeister \& Jones, 1978; Greenberg \& Pyszczynski, 1985; Steele, 1988), some threats primarily or exclusively arouse defenses within the domain of the threat.

Although Studies 1 and 2 showed that people distance themselves from violent and dishonest others if they have been led to believe that they possess an unusually high amount of those attributes, feedback of this nature is rare outside of social psychology laboratories. On the other hand, the personal experience of anger or guilt about dishonesty is probably fairly common. As suggested earlier, a primary reason people suppress their anger may be that they fear that their anger may lead them to engage in inappropriate behavior or acts of violence. If this were the case, then the personal experience of anger would be expected to lead to distancing from others who engage in angry aggression. The primary purpose of Study 3 was to test this hypothesis, thus extending our analysis to the effects of subjectively experienced emotions that imply the potential for unacceptable behavior. To this end, in Study 3 we investigated the effect of inducing anger in participants on their tendency to distance themselves from a violent other.

If defensive distançing from a violent person functions to deny one's own potential for destructive violence when angry, then the extent of distancing among angry participants would depend on what participants did with their anger. If participants express their anger in an appropriate or constructive way, they may no longer feel threatened by a potential for violence. Therefore, encouraging angry participants to verbally express their feelings may reduce their tendency to distance themselves from a violent other. Previous research by Pyszczynski et al. (1993) has shown a similar effect of constructive expression of emotion reducing both defensive distancing from a cancer patient and attitude change in the forced-compliance cognitive dissonance paradigm. Thus, a second purpose of Study 3 was to assess how opportunities to express angry feelings may affect distancing from a violent other.

\section{Study 3}

To address these issues, we induced participants to feel angry by giving them an insulting remark concerning their performance after they read a short speech. Other participants were not given an insulting remark. Of the participants who were insulted, some were given a chance to express their anger about being insulted, and others were not. All the participants then read about the same angry/violent target person and completed the distancing measure used in Study 1. We predicted that insulted participants who did not express their feelings would deny similarity to the violent person relative to noninsulted and insult-express participants.

\section{Method}

Participants. Twenty female and 14 male introductory psychology students at the University of Colorado at Colorado Springs participated in 
exchange for course credit. Participants were randomly assigned to one of three conditions in a single-factor design: insult-express, insult only, and no insult. ${ }^{5}$ Participants were run individually or in small groups ranging in size from 2 to 6.

Procedure. The experimenter began each session by telling participants that the study was concerned with how people use information to evaluate others. The experimenter then explained that to find out more about this evaluation process each participant would be asked to read a short speech to another student, who would be observing from behind a one-way mirror. Participants were also told that the other student was instructed to prepare a short evaluation of the participants' performance and that they would later have a chance to look over this evaluation. The experimenter explained further that to ensure honest responses, the evaluator was unaware that the participant would be looking over the evaluation.

At this point the experimenter left to retrieve the student evaluator and place this fictitious person in an adjacent room separated by a one-way mirror. After returning, the experimenter randomly assigned a speech for each participant to read that was either for or against affirmative action; the speech participants were assigned to read was varied randomly within each condition. Each speech was a little less than one page long and contained arguments that were mirror images of each other. Participants were given about $2 \mathrm{~min}$ to become familiar with the speech before reading it. When participants indicated that they were ready, the experimenter asked them to stand in front of the mirror and begin reading. Each participant presented his or her speech individually, with only the experimenter in the room. After the participant read the speech, the experimenter went into the next room, ostensibly to get the evaluation from the other student, and then returned with a sealed envelope and handed it to the participant. After all the participants in the session had finished reading their speeches, the experimenter asked them to wait a moment while he or she left to dismiss the student evaluator. On returning, the experimenter gave the participants permission to open their envelopes and read their evaluations.

Participants received an evaluation form consisting of four questions on which the evaluator had rated them using a 9-point scale. The first question asked "Is this person 'in favor of' or 'against' affirmative action?" The second question read, "How interested is this person in the topic they read about?" The third and fourth questions asked, "How convincing did this person sound?" and "Does this person agree or disagree with laws favoring minority groups?" A standard evaluation containing neutral ratings on each question was devised and given to each participant.

For participants in the insult-only condition and insult-express condition there was a "Comments" section at the bottom of this evaluation, with a handwritten insulting remark from the evaluator concerning the participant's performance. This insult read: "It is obvious that this person has trouble speaking in front of other people. All in all, their performance was pretty poor, not exactly an Oscar winner if you know what I mean!" Participants in the no-insult condition received identical numerical evaluations but no written comments. After participants looked at their evaluations they were instructed to put them away and move on to the next part of the experiment.

The remaining part of the experiment was described as a personality judgment task in which participants would receive some personality information about another student and then make some judgments about this person. Participants in the insult-only and no-insult conditions continued with this part of the experiment, but those in the insult-express condition were first asked to fill out a form. Participants in the insult-express condition were given a form encouraging them to express how they felt about being evaluated (i.e., insulted). This form contained a list of 10 emotive words ( 5 positive and 5 negative). The instructions on this form asked participants to select at least 2 words that most accurately reflected how they felt after being evaluated and to then describe their feelings beside each word. In addition to these written instructions, participants were told that sometimes in this study people have good or bad feelings about reading a speech and then being evaluated. Following procedures used by Pyszezynski et al. (1993) to encourage participants to express socially undesirable emotions, they were further told that "because psychological research has demonstrated a strong link between physical and mental health and an ability to accurately and freely express emotions, we would like to give you an opportunity to express your feelings." To make sure participants understood what to do, a sample form was shown to them that was supposedly filled out by a previous participant. This sample included a statement under the word hurt, which read "I felt hurt after seeing my evaluation. I know I am not very good at giving speeches, but I still felt hurt because I received a bad evaluation." This statement modeled the types of responses that were requested from participants in the insult-express condition.

All participants were then given a packet of information about a target person. This packet contained demographic information, a description of an emotional situation, and a personality inventory of the target person. The demographic information and the personality inventory were the same as in Study 1, but the description of the emotional situation was always the violent description. After inspecting this information, participants were told to fill out a short personality form. As in the previous studies, the experimenter pretended to be missing this form and left for $3 \mathrm{~min}$ to find it. On returning without the appropriate form, the experimenter resolved this problem by having participants make their self-ratings on the target's personality form.

After making their self-ratings, all participants were asked to fill out an evaluation form on the person who had previously evaluated them. On this form were four different questions related to the speech evaluator's social skills and skill as an evaluator: "How skilled is this person at making judgments about other people?", "How accurate do you think this person will be at rating other people's speeches?", "Would you guess that this person has excellent social skills or poor social skills?", and "Do you think this person would do better or worse than you if [he or she] had to read a speech?" The participants were required to rate the evaluator on a 9-point scale for each question, for which higher ratings indicated favorable responses. Participants then completed a form containing questions that served as manipulation checks. The first two questions asked participants to rate how violent the target person was and how similar to the target person they considered themselves to be. The last two questions asked participants how insulted they felt after receiving their speech evaluation and how nervous they felt while reading their speech. Ratings on each question were made on 9-point scales on which higher numbers indicated positive responses. After completing this questionnaire, participants were fully debriefed, thanked, given credit, and dismissed.

\section{Results and Discussion}

Manipulation checks. Separate one-way ANOVAs on participants' perceptions of how violent the target person was and how similar to the target person they considered themselves to be revealed no effect of treatment (both $p s>.25$ ). Given that all

\footnotetext{
${ }^{5}$ There was a fourth condition run in Study 3 intended to be an insult-revenge condition. The purpose of creating this condition was to assess whether people who take revenge on the insultor, out of aggression, would be particularly likely to distance themselves. In this condition, participants were insulted and then given the opportunity to evaluate the insultor prior to the measure of psychological distancing. The hope was that participants would derogate the insultor as a way of taking revenge. However, participants in this condition did not derogate the insultor any more than did participants in any of the other conditions; therefore, we could not assess the effects of taking revenge. Thus, we decided not to discuss this condition in the article. Detailed information about this condition is available from Jeff Schimel.
} 
Table 3

Manipulation Checks and Primary Dependent Measures: Study 3

\begin{tabular}{|c|c|c|c|c|c|c|}
\hline \multirow[b]{3}{*}{ Measure } & \multicolumn{6}{|c|}{ Anger condition } \\
\hline & \multicolumn{2}{|c|}{$\begin{array}{l}\text { Insult-violent target- } \\
\text { express }^{\mathrm{a}}\end{array}$} & \multicolumn{2}{|c|}{$\begin{array}{l}\text { Insult-violent target- } \\
\text { no express }\end{array}$} & \multicolumn{2}{|c|}{$\begin{array}{l}\text { No insult-violent } \\
\text { target-no express }\end{array}$} \\
\hline & $M$ & $S D$ & $M$ & $S D$ & $M$ & $S D$ \\
\hline Violent & 7.17 & 1.1 & 6.50 & 1.4 & 7.36 & 1.1 \\
\hline Similar & 3.33 & 1.9 & 2.54 & 1.4 & 3.27 & 1.9 \\
\hline Insulting & 6.08 & 1.9 & 4.64 & 2.3 & 3.09 & 2.2 \\
\hline Nervous & 4.50 & 1.8 & 5.18 & 2.4 & 4.45 & 1.4 \\
\hline Evaluations & 15.42 & 6.7 & 18.91 & 6.9 & 20.82 & 4.4 \\
\hline Distancing & 308.33 & 74.3 & 405.82 & 105.3 & 296.54 & 78.1 \\
\hline
\end{tabular}

Note. For all measures, high values reflect high levels of the variable in question.

${ }^{\mathrm{a}} n=12 .{ }^{\mathrm{b}} n=11 .{ }^{\mathrm{c}} n=11$.

participants evaluated the same violent target, this was as expected. These results indicate that the target person was perceived by participants as violent and as not similar to themselves in all conditions (all mean ratings of violence were greater than 6.54 , and all mean ratings of similarity were below 3.33; see Table 3). A one-way ANOVA on participants' ratings of how nervous they felt was also not significant $(p s>.50)$.

A one-way ANOVA on participants' ratings of how insulted they felt after receiving their evaluations revealed a significant effect of treatment, $F(2,31)=5.60, p<.01$. Pairwise comparisons indicated that participants in the no-insult condition felt less insulted than participants in the insult-express condition, $t(34)=3.35, p<.01$, and tended to be less insulted than participants in the insult-only condition, $t(34)=1.64, p<.11$. The insult-express condition and the insult-only condition did not differ from each other $(p>.50)$.

Distancing measure. As in Studies 1 and 2, we constructed a composite distancing score by summing the absolute value of the difference between participants' and the target person's ratings on the 20 personality traits. A one-way ANOVA on participants' composite distancing score revealed a significant treatment effect, $F(2,31)=5.33, p<.01$. Relevant means are presented in Table 3 . In support of our predictions, pairwise comparisons indicated that participants in the insult-only condition distanced themselves from the target person more than participants in the no-insult condition, $t(34)=2.95, p<.01$, or participants in the insult-express condition, $t(34)=2.69, p<$ .05 . The no-insult condition and the insult-express condition did not differ from each other $(p>.50)$. Thus, although being insulted increased participants' tendency to distance themselves from the violent target person, expressing one's own anger about the insult eliminated this need to distance.

Supplemental analysis. We also tested the alternative explanation that insulted participants simply felt worse after being insulted by another student and responded by rating themselves higher on the positive traits and lower on the negative traits than noninsulted participants did. Thus, distancing may have been a result of participants enhancing their self-evaluations. As in Studies 1 and 2 , we tested this alternative explanation by reverse coding participants' ratings on the 10 negative traits and summing them with the 10 positive traits to form a composite favorability score. A one-way ANOVA performed on this favorability score yielded no effects, indicating that participants' tendency to distance themselves from the target person was not due to more favorable self-ratings on the 20 personality traits (all $p s>.25$ ).

Ratings of the evaluator. A one-way ANOVA conducted on participants' ratings of the evaluator was not significant, $F(2$, $31)=2.30, p>.11$. However, this trend toward an effect reflected a tendency for insult-express participants to give lower mean evaluations than noninsulted participants (see Table 3 for means). It is possible that after insult-express participants expressed their feelings about being insulted, they felt less compunction about expressing their anger on a later evaluation of the person who insulted them. No other pairwise comparisons approached significance.

In sum, the results of Study 3 extend those of Studies 1 and 2 by supporting the hypothesis that inducing participants to feel angry increases their tendency to perceive themselves as dissimilar to an inappropriately violent person. Participants were more likely to rate their own personality as discrepant from the personality of a violent person when insulted than when not insulted. By perceiving themselves as different from a person who became destructively violent when angry, participants were presumably able to deny their own potential for violence, the fear of which was aroused by their feelings of anger. This fear of one's own potential for violence seemed to be aroused by both the experience of anger in Study 3 and by false feedback that one is high in repressed hostility in Studies 1 and 2.

Study 3 also offered an important extension of the previous findings by documenting a mechanism that serves to reduce psychological distancing. As predicted, participants who verbally expressed their anger after being insulted distanced themselves less from the violent target than participants who were insulted did. In fact, insult-express participants were no more likely to distance themselves from the violent person than were participants who were not insulted. If the act of expressing emotions reduced participants' tendency to psychologically distance themselves, then we would also expect more constructive emotional expression to be associated with less distancingthat is, the more participants were able to acknowledge their feelings and admit that their feedback made them feel upset or 
angry, the less they should have a need to distance themselves from the angry/violent target. On the other hand, if participants expressed their emotions in a way that was defensive or did not acknowledge that they were upset, then they should be more likely to distance themselves. To assess this relationship between the amount of constructive expression and distancing, independent raters (blind to conditions) coded the expression under each emotive word on insult-express participants' expression forms. The coders assigned a value of 1 to each expression in which the person was constructive (i.e., nondefensive) and assigned a value of -1 to each nonconstructive (i.e., defensive) expression in which the participant did not acknowledge his or her emotions. An example of a constructive expression was "I was hurt that I didn't get a good evaluation because I tried to give a good speech." Conversely, an example of a nonconstructive expression was " $\mathrm{My}$ evaluator was retarded because he couldn't realize that I was not giving a speech to thrill him." We then created a composite measure of constructive emotional expression by summing the ratings for the expression under each emotive word on participants' expression forms. There was high agreement between the two raters, $r(10)=.77$. However, disagreements were resolved through discussion to create a single composite constructive expression score. We then examined the correlation between distancing and constructive expression. This analysis showed a negative correlation between distancing and constructive emotional expression, $r(12)=-.70, p<.05$, which is consistent with our reasoning that expressing one's anger in a nondestructive verbal manner reduces the threat that one's anger may have violent consequences. Presumably this is because once one's anger is expressed and out in the open it seems more manageable and less likely to lead to dangerous consequences.

There are, however, plausible alternative explanations for the two key findings of Study 3. First, there is another way to account for the finding of increased distancing in the insult-only condition. It may be that angered participants who did not express their emotions distanced themselves from the violent target because they were in a unique emotional state in which they perceived themselves as different from anyone else. Because we included only the angry/violent target in Study 3, it is possible that anger may have led to distancing from any type of target rather than just a target who was violent.

There are also two alternative ways to account for the lack of distancing in the insult-express condition. It could be that participants in the insult-express condition did not feel insulted by the insulting remark. To encourage them to express their feelings, insult-express participants were shown a sample response from another student that ended with the statement "I still felt hurt because I received a bad evaluation." This comment may have led participants to believe that other people had received disparaging evaluations, too. Knowing that others did poorly on their speeches and received bad evaluations might have made the insulting remark seem less insulting. However, this explanation seems unlikely, because there was actually a nonsignificant trend for insultexpress participants to be more insulted than participants in the insult-only condition (see Table 3 for mean perceptions of insult in the three conditions). Another, more plausible explanation for the finding of reduced distancing in the insult-express condition is that because these participants took extra time to complete the expression form, they experienced a longer delay between anger provocation and the defensive distancing measure. Thus, because insult-express participants took more time to complete the expression form, their anger may have been reduced by the simple passage of time.

\section{Study 4}

To assess these alternative explanations and extend our general findings from the previous studies, we conducted a fourth study, which was a conceptual replication of Study 3. This study included the same three conditions as in Study 3 (insult only, insult-express, and no insult), but we added a condition in which we assessed angry participants' distancing from an angry nonviolent target. If angered participants are in a unique emotional state that leads them to distance themselves from anyone, then they should distance themselves from the nonviolent target as well as from the violent target. However, if angered participants distance themselves because they need to defend against their own potential for inappropriate violence, then they should distance themselves only from the violent target. To assess whether insult-express participants in Study 3 did not distance themselves from the violent target because their anger dissipated because of the passage of time, we introduced a filler task in the nonexpression conditions. If insult-express participants still distance themselves less than participants in the nonexpression conditions, then this would lend support to our notion that emotional expression attenuates the need for defensive distancing. In contrast, if insulted participants who experience a time delay do not distance themselves, then we would be unable to rule out the passage of time as an explanation for reduced distancing in the expression condition.

To this end, we induced participants in three of the four conditions to feel angry by giving them an insulting remark concerning their writing ability after they wrote a short essay. The remaining participants were not given an insulting remark. Some of the participants who were angered were given a chance to express their emotions concerning the feedback; others were instead given a filler task to control for the time delay. Participants then inspected some information about a target person. Participants who were angered but did not have a chance to express their emotions read about either a violent or a nonviolent target. All of the other participants read about the violent target. Therefore, the study included four conditions: insultviolent target, insult-nonviolent target, insult-violent targetexpress, and no insult-violent target. After reading about the target person, participants completed the same distancing measure that was used in the previous studies. As in Study 3, we predicted that insulted participants who did not express their emotions would distance themselves from the violent person relative to participants who were not insulted, expressed their emotions, or read about the nonviolent target.

\section{Method}

Participants. Twenty-five female and 18 male introductory psychology students at the University of Arizona participated in exchange for 
course credit. ${ }^{6}$ Participants were randomly assigned to one of four conditions in a single-factor design: insult-violent target, insult-nonviolent target, insult-violent target-express, and no insult-violent target. Participants were run in groups of 3-5.

Procedure. As in Studies 1-3, the experimenter began each session by telling participants that the study was concerned with how people use information to form impressions of others. The experimenter explained to participants that to investigate this process they would take part in two different activities. The first activity was described as a kind of guessing game. In this part of the study the participants were told that they would write an essay that another person in the study would read and evaluate. The evaluator would then try to guess the author's true attitudes on the basis of the essay. The experimenter then explained to the participants that although all of them would write an essay, only some of them would be asked to evaluate an essay. The rest of the participants would be asked to fill out another form that was being pretested for future research. The purpose of misleading participants in this way was to give them a rationale for why they would later be given a questionnaire to fill out (the emotional expression or delay form) instead of evaluating another person's essay. The experimenter then explained to the participants that they would also take part in a second activity that involved reading about another person who was not in the present study and making some judgments about that person.

After leading the participants into private cubicles, the experimenter assigned them to write a short essay in favor of or against affirmative action and told them to try and sound as convincing and persuasive as possible in their essays. To familiarize participants with the issue, the experimenter also gave the participants a list of arguments that corresponded to the side of the issue they were assigned to argue. When the participants were finished writing their essays, the experimenter collected the essays and gave the participants a filler questionnaire to complete while they waited for the other person to read and evaluate their essay. After about $5 \mathrm{~min}$, the experimenter handed the participants a sealed envelope and said

Okay, the other person finished reading your essay and filled out a short evaluation form. Before I give this to you, I just want you to know that I did not tell the other person that you would see this evaluation. The reason I did this is because I wanted the other person to be completely honest in their evaluation.

Participants in the insult conditions received an evaluation with an insulting remark, and participants in the no-insult condition received an evaluation without an insulting remark. The evaluation form was exactly the same as was used in Study 3, with one exception: The insulting, handwritten remark at the bottom of the evaluation was changed to fit the essaywriting procedure. The insulting remark read as follows:

This person is obviously a poor writer. Not only did I fall asleep reading their essay, but based on the arguments they gave supporting (opposing) affirmative action, I don't think they are aware of the really important issues. All in all, not exactly an award winning essay if you get my drift.

The insulting remark that participants received was always arranged so that it gave subtle mention to the side of the affirmative action issue they had been assigned to argue (i.e., supporting or opposing affirmative action). The purpose of tailoring the feedback to the participants' essays was to enhance the credibility and believability of the insulting remark. To further enhance the believability of the insult, a few crossed-out mistakes were added to make it look authentic.

After participants viewed the evaluation form and put it back into the envelope, the experimenter re-entered the cubicles, handed the participants another envelope, and said, "you may have guessed by now that you weren't one of the ones chosen to evaluate another person's essay. Instead, I have a couple of questionnaires for you to fill out that we are pretesting for future research." The envelope contained either the emotional expression form or the delay form and the short form of the Positive and Negative Affect Schedule (PANAS; Watson, Clark, \& Tellegen, 1988). Participants in the insult-violent-target-express condition received the emotional expression form, and participants in the other three conditions received the delay form. The emotional expression form and the instructions on how to fill it out were the same as those used in Study 3. The delay form consisted of 10 words taken from a sample SAT test with instructions telling participants that a pilot test of college students' general vocabulary was being conducted. Then, parallel to the instructions for the emotional expression form, participants were asked to define at least 2 of the 10 words in as much detail as possible. The words chosen were moderately difficult but simple enough so that all participants were able to easily define some of the words (e.g., agenda, novel, concise, deduce).

As in the first three studies, the experimenter then introduced the next part of the study by giving the participants a packet of information about the target person that contained demographic information, a self-authored description of an emotional situation, and a personality form. For participants in the insult-violent-target-express, insult-violent-target, and noinsult-violent-target conditions, the self-written description of an emotional situation was the same as the violent description (child abuser) used in Studies 1, 2, and 3. For participants in the insult-nonviolent condition the self-written description was the same nonviolent description used in Study 1. After looking through the target's information, participants were asked to fill out another personality form. Using the same procedure as in the first three studies, the experimenter pretended to be missing the forms and left for $3 \mathrm{~min}$ to find them. On returning, the experimenter resolved the dilemma by having participants make their self-ratings on the target's personality form.

In the final portion of the experiment, participants completed a questionnaire that contained some questions about the target person and some questions that served as manipulation checks. The questions that pertained to the target person asked "How violent was this person?" and "How appropriately did this person handle the situation?" Three additional questions asked participants about the feedback they received. These questions were: "Did you feel insulted by anything on the student's evaluation of your essay?", "Did anything on the evaluation form make you angry?", and "How accurate was the feedback you received?" Ratings on each item were made on 9-point scales, with higher numbers indicating higher ratings on the measures. After completing this form, participants were thoroughly debriefed, given credit, and dismissed.

\section{Results and Discussion}

Manipulation checks. We expected that participants in the insult-nonviolent-target condition would rate the target's behavior as less violent and more appropriate than participants in the other conditions who read about the violent target. A one-way ANOVA performed on participants' ratings of the target's violence revealed

\footnotetext{
${ }^{6}$ Only White participants were used in Study 4 . The reason for using only White participants is because the procedures of the study involved writing an essay either in favor of or against affirmative action and then receiving feedback about the essay. Thus, we wanted to avoid participants with a strong ethnic background who might have an especially strong emotional reaction to the essay and the feedback. This precaution was taken in Study 4 and not Study 3 because the student population from Study 3 (Colorado Springs, Colorado) was less ethnically diverse than the student population used in Study 4 (Tucson, Arizona). Furthermore, the feedback participants received in Study 3 was less related to the content of their speeches (the speech was already written for them) than it was to the essays participants wrote in Study 4, so we did not expect as extreme reactions from ethnic individuals in Study 3 .
} 
Table 4

Manipulation Checks and Primary Dependent Measures: Study 4

\begin{tabular}{|c|c|c|c|c|c|c|c|c|}
\hline \multirow[b]{3}{*}{ Measure } & \multicolumn{8}{|c|}{ Anger condition } \\
\hline & \multicolumn{2}{|c|}{$\begin{array}{c}\text { Insult-violent } \\
\text { target-no } \\
\text { express }^{\mathrm{a}}\end{array}$} & \multicolumn{2}{|c|}{$\begin{array}{l}\text { Insult- } \\
\text { nonviolent } \\
\text { target-no } \\
\text { express }^{\text {b }}\end{array}$} & \multicolumn{2}{|c|}{$\begin{array}{l}\text { Insult-violent } \\
\text { target-express }\end{array}$} & \multicolumn{2}{|c|}{$\begin{array}{l}\text { No insult- } \\
\text { violent target- } \\
\text { no express }{ }^{\mathrm{d}}\end{array}$} \\
\hline & $M$ & $S D$ & $M$ & $S D$ & $M$ & $S D$ & $M$ & $S D$ \\
\hline Violent & 7.1 & 0.8 & 2.9 & 1.4 & 7.1 & 1.8 & 6.5 & 1.3 \\
\hline Appropriate & 1.4 & 0.7 & 6.2 & 2.2 & 1.9 & 1.0 & 2.1 & 0.7 \\
\hline Angered & 5.0 & 2.4 & 5.7 & 2.5 & 5.6 & 3.2 & 2.7 & 1.6 \\
\hline Insulted & 5.6 & 2.5 & 6.5 & 2.5 & 6.4 & 2.9 & 4.8 & 2.2 \\
\hline Accurate & 4.0 & 2.6 & 4.6 & 2.5 & 3.1 & 2.1 & 5.4 & 2.1 \\
\hline Positive affect & 28.6 & 8.1 & 26.1 & 8.3 & 22.7 & 10.1 & 29.3 & 7.6 \\
\hline Negative affect & 17.0 & 5.7 & 16.4 & 4.3 & 17.6 & 3.2 & 18.5 & 7.2 \\
\hline Hostility & 1.7 & 1.0 & 1.7 & 1.0 & 1.8 & 1.3 & 1.4 & 0.7 \\
\hline Distancing & 413.9 & 77.8 & 318.3 & 81.0 & 328.5 & 54.3 & 336.3 & 73.9 \\
\hline
\end{tabular}

Note. For all measures, high values reflect high levels of the variable in question.

${ }^{\mathrm{a}} n=11 .{ }^{\mathrm{b}} n=10 .{ }^{\mathrm{c}} n=10 .{ }^{\mathrm{d}} n=12$.

a significant effect of treatment, $F(3,39)=22.32, p<.0001$. Means for this analysis are presented in Table 4 . In line with our expectation, pairwise comparisons revealed that participants in the insult-nonviolent condition perceived the target as less violent than participants in the insult-violent-target condition, $t(43)=7.04, p<.0001$; the insult-violent-target-express condition, $t(43)=6.97, p<.0001$; and the no-insult-violent-target condition, $t(43)=6.1, p<.0001$. We also performed a one-way ANOVA on participants' ratings of how appropriate the target's behavior was. This analysis revealed a significant effect of treatment, $F(3,39)=30.64, p<.0001$. Pairwise comparisons revealed that insult-nonviolent-target participants rated the target's behavior as more appropriate than participants in the insult-violenttarget condition, $t(43)=8.4, p<.0001$; the insult-violent-targetexpress condition, $t(43)=7.67, p<.0001$; and the no-insultviolent-target condition, $t(43)=7.59, p<.0001$

We also expected that participants who received an insulting remark on their evaluation would report being more angered by their evaluation and more insulted than those who did not receive an insulting remark. A one-way ANOVA performed on the question that asked participants if anything on their evaluation made them angry revealed a significant effect of treatment, $F(3$, $39)=3.52, p<.03$. Pairwise comparisons supported our prediction. Participants in the no-insult-violent-target condition reported being less angered than participants in the insult-violent-target condition, $t(43)=2.18, p<.05$; the insult-nonviolent-target condition, $t(43)=2.78, p<.01$; and the insult-violent-targetexpress condition, $t(43)=2.69, p<.05$. It is also worth pointing out that participants in the insult-violent-target-express condition reported being no less angered by their feedback than the other participants who were insulted (both $p s>.50$ ). This finding suggests that the reduction in distancing for insult-violent-targetexpress participants was not due to a reduction in their anger. A one-way ANOVA performed on how insulted participants were by their evaluation was not significant, $F(3,39)=1.01, p>.39$; however, the pattern of means showed that insulted participants reported being slightly more insulted than noninsulted participants (see Table 4). A one-way ANOVA performed on participants' ratings of the accuracy of their feedback revealed no significant effect of treatment, $F(3,39)=1.79, p>.16$; however, the pattern of means showed that participants in the insult-violent-targetexpress condition reported that their feedback was nonsignificantly less accurate than participants in the other conditions.

Affect. We performed one-way ANOVAs on the Positive Affect scale and the Negative Affect scale of the PANAS (short form). This analysis revealed no effect of treatment for positive or negative affect, $F(3,39)=1.31, p>.28$, and $F(3,39)=0.30, p>.82$, respectively. However, there was a slight trend for insult-violent-target-express participants to report less positive affect than participants in the other conditions (see Table 4 for means). There was one item on the PANAS that asked participants about their feelings of hostility. We performed a separate ANOVA on this item to see if participants in our insult conditions reported feeling more anger than participants in the other conditions. This analysis revealed no significant effect; however, the pattern of means showed that insulted participants indicated that they were more hostile than noninsulted participants, $F(3$, $39)=0.29, p>.82$. Means and standard deviations for the affect measures are presented in Table 4.

Distancing measure. As in the first three studies, we constructed a composite measure of distancing from the target person by summing the absolute value of the difference between participants' and the target's ratings on the 20 personality traits. ${ }^{7} \mathrm{~A}$ one-way ANOVA performed on this measure revealed a significant effect of treatment, $F(3,39)=3.90, p<.02$. In line with our

\footnotetext{
${ }^{7}$ One participant in our original sample had an extreme score $(2.5 S D$ above the mean) on the distancing measure. On the basis of recommendations by Kirk (1995), we dropped this participant's score from our final analysis. However, the one-way ANOVA including this outlier was still significant, $F(3,40)=2.94, p<.05$. The means for this analysis on the distancing measure were 413.90 (insult-violent target), 349.45 (insultviolent target-express), 318.30 (insult-nonviolent target) and 336.33 (no insult-violent target).
} 
predictions, pairwise comparisons showed that participants in the insult-violent-target condition distanced themselves more from the target person than did participants in the insult-nonviolent-target condition, $t(43)=3.0, p<.01$; the insult-violent-target-express condition, $t(43)=2.69, p<.05$; and the no-insult-violent-target condition, $t(43)=2.56, p<.05$. Cell means and standard deviations are presented in Table 4.

Supplemental analysis. Once again, we tested the alternative explanation that distancing may have been due to participants rating themselves higher on the 10 positive traits and lower on the 10 negative traits. Thus, as in the previous studies, we reverse coded participants' ratings on the 10 negative traits and summed them with the 10 positive traits to form a composite favorability score. An ANOVA performed on this favorability score yielded no effect $(p>.25)$, indicating that insulted participants' tendency to distance themselves from the violent target was not due to more favorable self-ratings on the 20 personality traits.

The results of Study 4 are in line with our findings from Studies 1 and 2 and extend the results of Study 3. As in Study 3, we found that inducing participants to feel angry increased their tendency to distance themselves from an angry/violent person relative to participants who were not angered. We also found that when participants were angered they rated themselves as different from the violent person but not from the nonviolent person. This finding lends support to our contention that angered participants' tendency to distance themselves from the angry/violent target in Studies 3 and 4 was due to a need to defend against the possible negative implications of their own anger and not to a general tendency to distance themselves from anyone.

As in Study 3, the results of Study 4 also showed that angered participants who were induced to express their emotions distanced themselves less from an angry/violent person than angered participants who did not express their emotions. We have argued that constructively expressing emotions about being insulted reduces one's need to defend against the negative implications of having the emotion, possibly because expressing the emotion reduces the threat that one's anger might lead to inappropriate behavior or other negative consequences. Although they were slightly weaker, correlational analyses between constructive emotional expression and distancing were consistent with this interpretation. Using the same procedure as in Study 3, we had independent raters code the emotional expression forms from Study 4 and found that the more constructive emotion participants expressed, the less they distanced themselves from the angry/violent target, $r(10)=-.48$, $p<.16$.

As we mentioned previously, one limitation of Study 3 was that participants in the emotional expression condition took more time to complete the expression form. However, by adding a time delay to the nonexpression conditions in Study 4, we were able to rule out the alternative explanation that participants in the insultviolent-target-express condition distanced themselves less because the longer delay gave them more time to "cool down" after being angered. To be sure that nonexpression participants took about as much time on their filler task as expression participants took to complete their forms, we also computed means for the number of words participants defined or used to express their emotions. We found that the mean number of words defined by nonexpression participants $(M=4.1)$ was actually greater than the mean number of expressions given by insult-violent-target- express participants $(M=2.1)$. Thus, despite probably taking less time, participants who were given the opportunity to express their emotions still distanced themselves less from the violent target.

Another interesting finding from Study 4 was that angered participants in the insult-violent-target-express condition were just as likely to report being angered by their evaluation as participants who did not express their emotions. Thus, it seems that the decrease in distancing that occurred for the insult-violenttarget-express participants was not due to a reduction in their anger. This finding is consistent with our previous analysis that it is not the anger itself that motivates distancing; rather, it is the negative implication (e.g., the potential for violence or other inappropriate behavior) that anger has for the self that motivates angry participants to distance. Also in line with this analysis is the finding that angered participants distanced themselves from the violent person but did not distance themselves from the nonviolent person. When participants were angered, they distanced themselves from another person only when the person's anger led to inappropriate negative consequences. Once again, this finding suggests that it is not the emotion itself that led participants to distance but the possibility that anger might lead to the socially deplorable act of violence.

\section{General Discussion}

The four studies reported in this article provide converging support for the proposition that people distance themselves from others who have undesirable characteristics that they fear in themselves. Specifically, when concerned about their own anger, participants distanced themselves from an inappropriately violent person by perceiving their own personalities as highly distinct from this person. In Study 1, participants who were given false feedback that they had a great deal of repressed anger were more likely to psychologically distance themselves from a person who acted violently in response to anger than were participants who read about a nonviolent angry target or participants who were led to believe they were low in repressed anger. Study 2 replicated this effect and extended its generality by showing that people who were led to believe that they were high in repressed dishonesty distanced themselves from a person who behaved in a blatantly dishonest manner and, most important, demonstrated that this distancing is driven by a motive to deny one's potential for a specific undesirable behavior rather than a motive to deny one's similarity to people with more general negative characteristics. Whereas participants who were given repressed-anger feedback distanced themselves from the violent person but not from the dishonest one, participants who were given dishonesty feedback distanced themselves from the dishonest person but not from the violent one. Study 3 extended the evidence for defensive distancing to people who actually experience a negative emotion with implications for undesirable behavior: The tendency to distance themselves from a violent person was increased among participants who were made to feel angry by an insult from another person. Expressing these feelings of anger also reduced this tendency to defensively distance. Finally, Study 4 was in line with our overall findings and extended the results of Study 3 by demonstrating that angry participants distanced themselves only from the angry/violent target and that the reduced distancing among participants given the opportunity to express their emotions was not 
simply due to the passage of time. The results of this research therefore provide converging support for the proposition that the tendency to psychologically distance oneself from others is affected not only by the other person's qualities and one's own but also by the relationship between the other's qualities and aspects of oneself that one fears or wishes to deny.

It is important that Study 1 revealed no sign of distancing from the angry/violent person among participants who were given feedback that they were in the low-to-normal range for repressed anger. The fact that defensive distancing emerged only among participants given high anger feedback suggests that the tendency to distance oneself is not merely a negative reaction to the behavior of the target person but rather a specific response to the fear of similar tendencies within oneself. Furthermore, high anger feedback participants did not distance themselves from the angry target person who responded to his or her anger in an appropriate way. This suggests that it is the potential for inappropriate violence that is frightening about anger, rather than some other aspect of the experience. The present findings suggest that people who fear that their anger may lead to inappropriate violence to defensively distance themselves from others who respond to their own anger with violence in order to deny this potential within themselves.

\section{The Nature of Psychological Distancing as a Defense}

These findings are consistent with Jung's general notion that people actively defend themselves against their shadows- undesirable aspects of self that people fear and would rather not acknowledge. Whereas Jung emphasized projection, the overperception of these feared characteristics in others, as the typical defense against one's shadow, the present findings suggest that psychological distancing may also be a relatively common defensive response. By seeing oneself as different from those who harbor characteristics that one fears in oneself, one is able to implicitly deny one's potential for the dreaded characteristic or behavior, in effect enabling one to say "I would never do that, I'm not that kind of person." The foregoing analysis assumes that perceptions of similarity to a person on any given dimension increase the subjective likelihood that one is similar on other dimensions. This proposition can be derived from a variety of theories (e.g., Festinger, 1954; Heider, 1958; Kahneman \& Tversky, 1972; Kelley, 1967) and is supported by a fairly large body of social cognitive research (e.g., Gilovich, 1981; Wood, 1989). Apparently, people are not always good at differentiating irrelevant from relevant dimensions from which valid predictions of future behavior can be logically deduced. The present findings suggest that people's inferences about the implications of their similarity to others are probably based more on a "quick and dirty" heuristic form of processing than on a thorough logical analysis of the available data (cf. Kahneman \& Tversky, 1972; Petty \& Cacioppo, 1986).

This assumption-that similarity on one dimension implies similarity on other dimensions-is consistent with the widely held view that emotional threats are based more on simple associative linkages between cognitive elements than on well-reasoned logical implications. Freud (1960) argued that the unconscious, where most psychological threats are played out, entails a primitive form of thought unencumbered by the rules of logic. More recently, Epstein (1994) argued that emotional processing is essentially experiential in nature, driven by simple associations from prior experiences rather than rational analysis. Indeed, most forms of cognitive therapy are based on the assumption that maladaptive emotions derive from irrational beliefs about the implications of our thoughts, feelings, and characteristics (e.g., Beck, 1967; Ellis, 1962). The irrational nature of defending oneself against one's potential for responding to one's anger with violence by perceiving oneself as different from a target person on dimensions that are irrelevant to anger and violence-such as neatness, wit, restlessness, and clumsiness - is consistent with the assumption that only a relatively low level of cognitive analysis is typically involved in the experience of this type of psychological threat.

\section{Effects of Emotional Expression on Defense}

The present findings are also in line with the contention that expressing undesired emotions reduces the defensive maneuvers that function to diffuse these emotions. When participants were encouraged to express their emotional reactions to the insult they received in Study 3, it completely eliminated their tendency to respond to their anger with distancing from the violent target person. This is consistent with Pyszczynski et al.'s (1993) finding that the expression of feelings of tension reduces the tendency to change one's attitude in a dissonance-reducing direction in the induced-compliance paradigm and that the expression of fear reduces the tendency to distance oneself from a cancer patient. Pyszczynski et al. (1993) argued that emotional expression reduces defensiveness, because once the emotion is expressed, it is usually too late for the defensive maneuver to fulfill its emotion-denying function and that, furthermore, expressing the emotion may help people realize that the unpleasant emotion is tolerable and not worth defending against. However, in the present research the participants' defensive reaction was not against an emotion per se but against possible negative implications of the emotion for the self (i.e., a potential for inappropriate violence). By expressing their anger and hurt, participants displayed a nonviolent reaction to their anger and thus saw no need to convince themselves that they were different from the violent target person. If participants realized that their anger was unlikely to lead to dangerous consequences, then seeing themselves as similar to a violent person would be less threatening. Consistent with this analysis, the more constructively participants expressed their anger, the less they distanced themselves from the angry/violent target. Although the findings of the studies reported in this article provide additional evidence that expressing emotions reduces defensiveness, further exploration of the processes underlying the effect of emotional expression on the reduction of motivated biases is needed.

\section{Conclusion}

The present findings provide evidence that people are threatened by undesirable features of others that they fear in themselves and that they respond to this threat by psychologically distancing themselves from such individuals. These findings provide broad support for a number of potentially important ideas. At the intergroup level, it has been suggested that people with strong negative stereotypic beliefs may derogate and distance themselves from out-group members, in part because of the threat that they themselves may possess a trait stereotypically ascribed to that group 
(Allport, 1954). Recall that Jung (1951/1959) argued that the projection of the shadow onto out-groups contributed to stereotyping and prejudice. Similarly, a cheap person may not only view Jews as cheap but may also disassociate from them: "I'm not like those Jews." As another example, a Euro-American who fears his or her own lack of intelligence, violence, or sexual impulses may want to see him- or herself as very different from African Americans, who are stereotyped with those qualities. Perhaps this is why highly homophobic men have been found to be sexually aroused by homosexual erotic stimuli (Adams et al., 1996).

We suggested that at the interpersonal level parents and offspring may have difficulties getting along, in part because they see their own undesirable qualities in each other. Broadly consistent with this idea is Tesser's (1980, Study 3) finding that famous fathers had difficulties getting along with sons who went into the same profession. As Tesser $(1980,1988)$ argued, this may be because of the relevance of comparison when the career is the same. It also is possible, however, that this occurs because fathers and sons who go into the same occupation also share many personality traits. The present work fits this idea by showing that attributes we fear in ourselves lead us to distance ourselves from others who have these characteristics.

The present findings also show that verbal expression of anger reduces this tendency to defend against the implications of one's anger. Taken as a whole, this research suggests that interpersonal behavior may be affected in socially significant ways by fears we have concerning the shadows within us all.

\section{References}

Adams, H. E., Wright, L. W., \& Lohr, B. A. (1996). Is homophobia associated with homosexual arousal? Journal of Abnormal Psychology, $105,440-445$.

Alicke, M. D. (1985). Global self-evaluation as determined by the desirability and controllability of trait adjectives. Journal of Personality and Social Psychology, 49, 1621-1630.

Allport, G. W. (1954). The nature of prejudice. Reading, MA: AddisonWesley.

Aronson, E. (1972). The social animal. New York: Viking.

Baumeister, R. F., \& Jones, E. E. (1978). When self-presentation is constrained by the target's knowledge: Consistency and compensation. Joumal of Personality and Social Psychology, 36, 405-417.

Baumeister, R. F., \& Leary, M. R. (1995). The need to belong: Desire for interpersonal attachments as a fundamental human motivation. Psychological Bulletin, 117, 497-529.

Beck, A. T. (1967). Depression: Clinical, experimental, and theoretical aspects. New York: Harper \& Rowe.

Bowlby, J. (1969). Attachment and loss: Vol. 1. Attachment. New York: Basic Books.

Brewer, M. B. (1979). In-group bias in the minimal intergroup situation: A cognitive motivational analysis. Psychological Bulletin, 86, 307-324.

Byrne, D., \& Blaylock, B. (1963). Similarity and assumed similarity of attitudes between husbands and wives. Journal of Abnormal and Social Psychology, 67, 636-640.

Cialdini, R. B., Borden, R. J., Thorne, A., Walker, M. R., Freeman, S., \& Sloan, L. R. (1976). Basking in reflected glory: Three (football) field studies. Journal of Personality and Social Psychology, 39, 406-415.

Crocker, J., \& Luhtanen, R. (1990). Collective self-esteem and ingroup bias. Journal of Personality and Social Psychology, 58, 60-67.

Ellis, A. (1962). Reason and emotion in psychotherapy. Secaucus, NJ: Lyle Stuart.
Epstein, S. (1994). Integration of the cognitive and psychodynamic unconscious. American Psychologist, 49, 709-724.

Festinger, L. (1954). A theory of social comparison processes. Human Relations, 7, 117-140.

Freud, S. (1960). The psychopathology of everyday life. (Vol. 6, standard ed.). London: Hogarth Press.

Gibbons, F. X., Gerard, M., Lando, H. A., \& McGovern, P. G. (1991). Smoking cessation and social comparison: The role of the "typical smoker." Journal of Experimental Social Psychology, 27, 239-258.

Gilgun, J. F., \& Reiser, E. (1990). The development of sexual identity among men sexually abused as children. Families in Society, 71, 515523.

Gilovich, T. (1981). Seeing the past in the present: The effect of associations to familiar events on judgments and decisions. Journal of Personality and Social Psychology, 44, 1110-1126.

Granberg, D., \& King, M. (1980). Cross-lagged panel analysis of the relation between attraction and perceived similarity. Journal of Experimental Social Psychology, 16, 573-581.

Greenberg, J., \& Pyszczynski, T. (1985). Compensatory self-inflation: A response to the threat to self-regard of public failure. Journal of Personality and Social Psychology, 49, 273-280.

Heider, F. (1958). The psychology of interpersonal relations. New York: Wiley.

Higgins, E. T. (1996). The "self digest": Self-knowledge serving selfregulatory functions. Journal of Personality and Social Psychology, 71, 1062-1083.

Jung, C. G. (1959). Aion researches into the phenomenology of the self (R. F. C. Hull, Trans.). In H. Reed, M. Fordham, \& G. Adler (Eds.), The collected works of $C$. G. Jung (Vol. 9, Part 2). Princeton, NJ: Princeton University Press. (Original work published 1951)

Jung, C. G. (1970). Mysterium junctions (R. F. C. Hull, Trans.). In H. Reed, F. M. Fordham, \& G. Adler (Eds.), The collected works of $C$. $G$. Jung (Vol. 14). Princeton, NJ: Princeton University Press. (Original work published 1959)

Kahneman, D., \& Tversky, A. (1972). Subjective probability: A judgment of representativeness. Cognitive Psychology, 3, 430-454.

Kelley, H. H. (1967). Attribution theory in social psychology. In D. Levine (Ed.), Nebraska Symposium on Motivation (Vol. 15, pp. 52-81). Lincoln: University of Nebraska Press.

Kirk, R. E. (1995). Experimental design: Procedures for the behavioral sciences. Pacific Grove, CA: Brooks/Cole.

Marks, G., \& Miller, N. (1982). Target attractiveness as a mediator of assumed attitude similarity. Personality and Social Psychology Bulletin, 8, 728-735.

Marks, G., Miller, N., \& Maruyama, G. (1981). The effects of physical attractiveness on assumptions of similarity. Journal of Personality and Social Psychology, 41, 198-206.

Markus, H., \& Nurius, P. (1986). Possible selves. American Psychologist, 41, 954-969.

Markus, H., \& Nurius, P. (1987). Possible selves: The interface between motivation and the self-concept. In K. Yardley \& T. Honess (Eds.), Self and identity: Psychosocial perspectives (pp. 157-172). Chichester, England: Wiley.

Ogilvie, D. M. (1987). The undesired self: A neglected variable in personality research. Journal of Personality and Social Psychology, 52, 379385.

Petty, R. E., \& Cacioppo, J. T. (1986). The elaboration likelihood model of persuasion. In L. Berkowitz (Ed.), Advances in experimental social psychology (Vol. 19, pp. 123-205). New York: Academic Press.

Pyszczynski, T., Greenberg, J., Solomon, S., Cather, C., Gat, I., \& Sideris, J. (1995). Defensive distancing from victims of serious illness: The role of delay. Personality and Social Psychology Bulletin, 21, 13-20.

Pyszczynski, T., Greenberg, J., Solomon, S., Sideris, J., \& Stubing, M. J. (1993). Emotional expression and the reduction of motivated cognitive 
bias: Evidence from cognitive dissonance and distancing from victims' paradigms. Journal of Personality and Social Psychology, 64, 177-186.

Rank, O. (1931). Psychology and the soul. New York: Perpetua.

Siegel, J. M. (1986). The Multidimensional Anger Inventory. Journal of Personality and Social Psychology, 51, 191-200.

Snyder, C. R., Lassegard, M., \& Ford, C. E. (1986). Distancing after group success and failure: Basking in reflected glory and cutting off reflected failure. Journal of Personality and Social Psychology, 51, 382-388.

Steele, C. M. (1988). The psychology of self-affirmation: Sustaining the integrity of the self. In L. Berkowitz (Ed.), Advances in experimental social psychology (Vol. 21, pp. 261-302). Orlando, FL: Academic Press.

Stone, J., Wiegand, A., Andrew, W., Cooper, J., \& Aronson, E. (1997). When exemplification fails: Hypocrisy and the motive for self-integrity. Journal of Personality and Social Psychology, 72, 54-65.

Tajfel, H. (1982). Social psychology of intergroup relations. Annual Review of Psychology, 33, 1-39.

Tajfel, H., \& Turner, J. C. (1979). An integrative theory of intergroup conflict. In W. G. Austin \& S. Worchel, (Eds.), The social psychology of intergroup relations (pp. 33-47). Monterey, CA: Brooks/Cole.
Tesser, A. (1980). Self-esteem maintenance in family dynamics. Journal of Personality and Social Psychology, 39, 77-91.

Tesser, A. (1988). Toward a self-evaluation maintenance model of social behavior. In L. Berkowitz (Ed.), Advances in experimental social psychology (Vol. 21, pp. 181-227). San Diego, CA: Academic Press.

Tesser, A., \& Cornell, D. P. (1991). On the confluence of self processes. Journal of Experimental Social Psychology, 27, 501-526.

Watson, D., Clark, L. A., \& Tellegen, A. (1988). Development and validation of brief measures of positive and negative affect: The PANAS scales. Journal of Personality and Social Psychology, 54 1063-1070.

Wood, W. (1989). Theory and research concerning social comparison of personal attributes. Psychological Bulletin, 106, 231-248.

Received June 10, 1996

Revision received July 2, 1999

Accepted August 10, 1999 